\title{
The importance of the study of igneous rocks and compositions to constrain the martian planetary evolution
}

Arya Udry', Justin Filiberto², Juliane Gross ${ }^{3}$, Mariek Schmidt ${ }^{4}$, Deanne Rogers ${ }^{5}$, Libby Hausrath', Roger Wiens ${ }^{6}$, and Nina Lanza 6

'Department of Geosciences, University of Nevada Las Vegas, 4505 S. Maryland Pkwy, Las Vegas, NV 890154, (arya.udry@unlv.edu); 'Lunar and Planetary Institute, USRA, 3600 Bay Area Blvd., Houston, TX 77058, USA, ${ }^{3}$ Department of Earth and Planetary Science, Rutgers University, Piscataway, NJ 08854; ${ }^{4}$ Department of Earth Sciences, Brock University, St. Catharines, ON L2S 3AT, Canada; 5 Department of Geoscience, Stony Brook University, Stony Brook, NY 11794; ${ }^{5}$ Space and Planetary Exploration Team, Los Alamos National Laboratory, Los Alamos, NM 87545.

\section{A white paper for the Planetary Science Decadal Survey (submitted July 2020)}

Signatories: Paula Antoshechkina | Rosalind Armytage | Brian Balta | David Baratoux | Jessica Barnes | David Beaty | Pierre Beck | Jeremy Bellucci | Lydie Bonal | Audrey Bouvier | Michael Bramble | Alan Brandon | Maryjo Brounce | Adrian Brown | Paul Byrne | Kevin Cannon | Fanny Cattani | Matthew Chojnacki | Charles Cockell | Max Collinet | Catherine Corrigan | Agnes Cousin | Luke Daly | Jemma Davidson | James Day | Vinciane Debaille | Emilie Dunham | Christopher Edwards | Cécile Fabre | Alberto Fairén | Jessica Flahaut | Lucy Forman | Esteban Gazel| Timothy Goudge | Sammy Griffin | Amber Gullikson | Lydia Hallis | James Head | Chris Herd | Briony Horgan | Geoffrey Howarth | Andréa Hughes | Munir Humayun | Hope Ishii | Devanshu Jha | Jeff Johnson | James Karner | Walter Kiefer | Thomas Kruijer | Tom Lapen | Laetitia Le Deit | Martin Lee | Robert Lillis | Jean-Pierre Lorand | Prajkta Mane | Harry McSween | Etienne Médard | Joe Michalski | Evan O'Neal | Amanda Ostwald | Lu Pan | Valérie Payré | Anne Peslier | Jennifer Piatek | Ana-Catalina Plesa François Poulet | Elizabeth Rampe | William Rapin | Eleni Ravanis | Lucie Riu | Steve Ruff | Mark Salvatore | Alison Santos | Violaine Sautter | Susanne Schwenzer | Noel Scudder | Justin Simon | Kathryn Stack | Kimberly Tait | Jeffrey Taylor | Allan Treiman | Kathleen Vander Kaaden | Christina Viviano | Meenakshi Wadhwa | Nathan Williams. 


\section{Executive summary:}

This white paper summarizes the scientific importance of studying igneous compositions in meteorites, surface samples, and through orbital analyses to better constrain the geology of Mars as a whole and better understand the geological processes that have shaped Mars in the past and present. In support of martian igneous studies, we strongly advocate for the following in the upcoming decade:

1. To sustain funding for meteorite recovery in order to have continued access to martian samples;

2. To support the return of igneous samples from Jezero crater;

3. To support funding for detailed analyses of igneous rocks at the martian surface;

4. To support laboratories and collaborations between sample, remotesensing, and mission scientists;

5. To support curation facilities needed for not only meteorite samples, but also Mars sample return.

The study of martian igneous compositions is crucial to the entire planetary community as it will help us to resolve questions about the formation and evolution of planetary interiors, climate and atmospheres, as well as habitability throughout the entire solar system.

\section{Current Mars igneous knowledge and datasets:}

Igneous Mars represents a fascinating and unique data point in the inner solar system. Igneous rock compositions and mineralogies inform us about the martian interior (mantle reservoir compositions, magmatic processes, and volatile inventory), the martian surface (including volcanic and hydrothermal processes), the bulk composition of Mars, formation, differentiation and evolution of the planet, and allow for comparison with the other planets in our solar system. Mars' lack of plate tectonics has resulted in preservation of early Noachian crust, giving us a window into early magmatic processes that is almost entirely lacking on our own planet.

To assess the planet's composition and mineralogy, and more broadly, its geologic and planetary evolution, we use several types of analyses, including:

1) Martian meteorites, which are the only physical samples that we possess to date. We currently have 141 paired meteorite groups in our collection originating from $>11$ ejection sites, spanning crystallization ages from 4.4 Ga (pre-Noachian) to $150 \mathrm{Ma}$ (mid-Amazonian), although no meteorites with ages between $4.1 \mathrm{Ga}$ and 2.4 Ga have been recovered so far. All martian meteorites but two - Northwest Africa 7034 and pairs, a polymict regolith breccia and Allan Hills (ALHA) 84001 - are igneous with mafic to ultramafic compositions (Udry et al., 2020). Martian meteorites are extremely valuable 
because, as the only martian samples, they can be studied in Earth-based state-of-the-art laboratories.

2) Surface in situ analyses, conducted by rovers and landers since 1976. Surface analyses provide field context and have sample terrains dating around the Noachian (4.7 - $3.7 \mathrm{Ga}$ ) to Hesperian (3.7 - $3.0 \mathrm{Ga}$ ) times, which are not represented in the martian meteorite collection. Compositions examined in situ range from ultramafic to evolved alkaline (McSween et al., 2006; Sautter et al., 2015; Squyres et al., 2006). Additional geochemical and mineralogical instruments onboard landed spacecraft (APXS, PIXL, ChemCam, SuperCam, and CheMin) provide important, complementary datasets that together, have yielded understanding of igneous compositions and histories on Mars, including variable mantle source characteristics, and melting and crystallization processes (Schmidt \& McCoy, 2010; Udry et al., 2018).

Meteorites

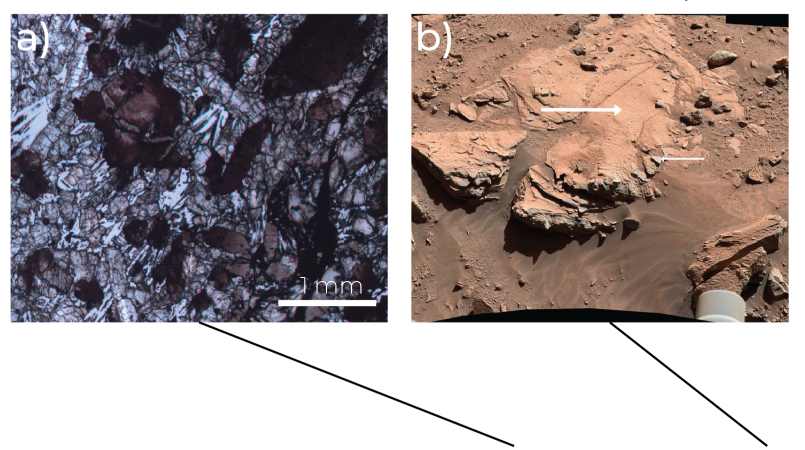

Study of igneous compositions through different tools

to better constrain igneous processes, sedimentary cycle, and habitability

\section{Orbital analyses}
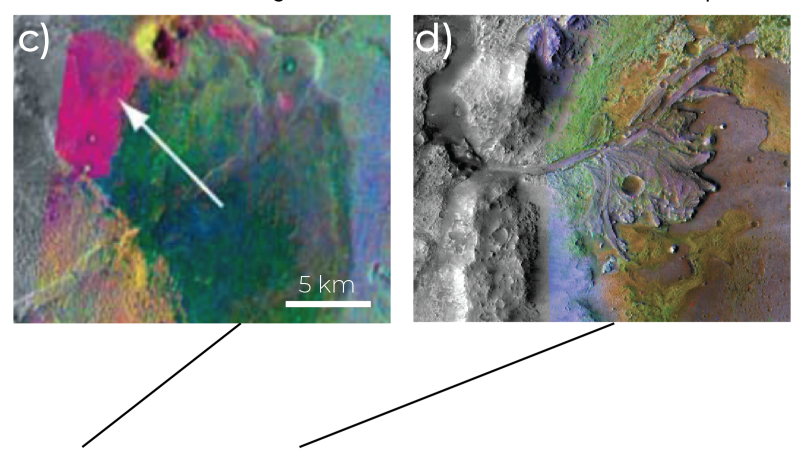

Figure 1. The different datasets with which to study igneous compositions: a) Meteorites: Northwest Africa (NWA) 4468 poikilitic shergottite in crosspolarized light; b) Surface targets: from Treiman et al. (2016): Windjana drill target and surroundings (NASA image PIA 18087); c) Orbital analyses: THEMIS false color image from Christensen et al. (2005), arrow points to dacitic flow over olivine-rich floor of Nili Patera caldera; and d) Returned samples: Jezero crater combined image of Compact Reconnaissance Imaging Spectrometer for Mars and the Context Camera from NASA/JPL/JHUAPL/MSSS/Brown University.

3) Orbital analyses, which help constrain martian global geologic context. The martian surface mainly consists of plagioclase, pyroxene, and olivine (Christensen et al. 2001), which are all igneous minerals. Visible images have revealed the omnipresence of volcanic features on the martian surface from the early history of Mars to the near-present (Werner, 2009). Global variations in elemental distributions and mineral assemblages show correspondence with major geologic terrains and reveal changes in mantle partial melting and 
magmatic evolution with time (Christensen et al., 2005; Rogers \& Hamilton, 2015; Taylor et al., 2010).

The study of martian igneous rocks from meteorites, surface missions, and from orbital data suggest mostly basaltic to ultramafic compositions, and their differences in their elemental compositions, mineralogies, and textures represent diverse mantle sources, and magmatic (e.g., fractional crystallization) and emplacement processes (Udry et al., 2020). Through new and state-of-the-art analyses, we have recently discovered that the martian interior is relatively complex for a planet without plate tectonics (Udry et al., 2020). The study of samples, particularly, have led us to a better understanding of the timing of many geologic processes, including early processes such as the fast accretion and differentiation (see Udry et al., 2020 for a summary). Rare, evolved rocks (enriched in $\mathrm{Si}, \mathrm{Na}$, and $\mathrm{K}$ ) also occur on the martian surface. The Curiosity rover mission has given us a unique glimpse of Noachian rocks not sampled by the Mars Exploration Rover (MER) generation of rovers. Igneous compositions in Gale crater found in sediments as well as orbital data indicate that Mars clearly possesses evolved rocks showing feldspar-rich (Rogers and Nekvasil, 2015) and even potentially nepheline-rich (Stolper et al., 2013) and peraluminous (Forni et al., 2015) compositions, but essentially devoid of quartz (e.g., Sautter et al., 2015; Cousin et al., 2017). Evolved lithologies have been formed throughout the entirety of martian history by different processes (including fractional crystallization and metasomatism) and might potentially show the presence of various sources and magmatic processes.

Various analyzed igneous lithologies have undergone secondary hydrous alteration and/or hydrothermalism, both seem to have occurred throughout the entire martian geologic history. On Mars, igneous compositions are also represented in sedimentary clastic rocks, (including olivine-rich sandstones), which are all derived from basaltic protoliths, differing from terrestrial clastic rocks, which are mostly felsic.

The Mars 2020 rover Perseverance is launching this year with a new set of instruments for the study of igneous rocks. These include two Raman spectrometers, an infrared spectrometer, a fine-scale XRF instrument, and a LIBS instrument (with additional infrared and LIBS instruments on Tianwen-7, the Chinese rover). In addition to the tools that we currently use, $\geq 31$ returned samples from Jezero crater are expected to be available for study as early as 2031. Perseverance will collect samples at Jezero crater, which from remotesensing data appears to contain igneous rocks with limited alteration and igneous mineral-bearing sedimentary units with a large range of ages, from a $\sim 4.0 \mathrm{Ga}$ Noachian brecciated crust, and an olivine-rich unit altered in Mgcarbonates, to a $2.6 \mathrm{Ga}$ Amazonian possibly volcanic unit (Goudge et al., 2015). The different igneous and sedimentary units in Jezero crater are basaltic in composition and/or contain a large amount (>50\%) of igneous minerals, including pyroxene, olivine, and plagioclase (Salvatore et al., 2018). The Mars 
2020 mission will provide us with the opportunity to study and bring back to Earth a variety of lithologies from Jezero crater, including igneous rocks and sedimentary rocks with igneous protoliths, which likely formed from the Noachian to the Amazonian. Returned samples from Mars will allow us to better constrain the compositions of the martian interior, including volatile content, and would provide important chronological context constraints, not only for Mars, but through extrapolation for the entire solar system. HesperianNoachian igneous pristine samples and altered igneous samples would allow to better define the alteration processes occurring during these times. Datable returned samples (based on radiogenic isotopes) would allow for an understanding of thermal evolution, volcanic history, and environmental transitions on Mars. Due to their constrained field context and datable ages, returned samples will be a strong complement to martian meteorites.

\section{What do we still do not know about martian geology?}

The three different datasets mentioned above have helped us to better constrain the geology and evolution of Mars since 1965. However, questions still remain about martian geological processes that may be inferred from igneous compositions (see Udry et al., 2020) that can be answered by newly recovered meteorites, new surface and orbital analyses, and future returned samples. For example:

- How variable in composition is the martian interior, including the crust and mantle? When and how did the variability happen?

- How did the magma ocean crystallize?

- How has melt generation, migration, and composition evolved with time on Mars?

- How were volcanic rocks emplaced at the martian surface?

- What is the volatile content in the interior and how did it evolve?

- What types of alteration of igneous rocks (including hydrous alteration) occurred and what are their extent at the martian surface?

- What was the history of the martian dynamo prior to its demise?

\section{Why are igneous rocks important to martian geology?}

The importance of studying igneous rocks is directly linked to several MEPAG goals (version 2020): Goal III: "Understand the origin and evolution of Mars as a geological system", "A. Document the geologic record preserved in the crust and investigate the processes that have created and modified that record"; and "B. Determine the structure, composition, and dynamics of the interior and how it has evolved"; Goal IIA "Characterize the state and 
controlling processes of the present-day climate of Mars under the current orbital configuration", and Goal 1A "Search for evidence of life in environments that have a high potential for habitability and preservation of biosignatures."

\section{Understand the origin and evolution of Mars as a geological system}

Basaltic rocks dominate the rock cycle within the martian crust and are therefore key to unraveling the history of Mars. Over the past decade, the investigation of Gale crater and the recovery of a large number of meteorites revealed diverse martian igneous lithologies and compositions, including evolved rocks (Udry et al. 2020). These newly observed compositions indicate the potential for a complex martian interior with occurrence of more mantle magmatic sources and complex magmatic processes on Mars than previously thought. Igneous compositions allow for age dating analyses, which can help us constrain the timing of interior processes, such as crustal development, but also the timing of the martian dynamo, through magnetic mineral analyses.

\section{Understanding past climates and atmospheres}

Igneous rocks have helped to unravel the availability of volatiles and amount of degassing across martian history. As determined in the iMOST report (IMOST 2018) for objective 4: "Understanding martian volatiles is essential both to astrobiology strategy and to the evolution of Mars as a planetary object." Liquid water is essential to life, and its main source is magmatic water. Volatile degassing is linked to habitability of the crust because degassing of the interior, either through crystallization of a magma ocean or being brought to the surface dissolved in magmas, presumably provided the majority of the volatile elements we see in the crust. Magmas provide other essential elements for life to the crust either through degassing (C, H, O, and S) or through alteration (P) (Westall et al., 2018). In addition, volatiles in magmas contribute to the atmosphere of Mars and play a key role in climate evolution (Filiberto et al., 2019).

\section{Understanding and finding habitable environments}

Constraining igneous compositions and processes on Mars is necessary to better understand the origin of sedimentary/hydrothermal rocks as well as alteration processes and habitability. Igneous rocks on Mars represent the protoliths of altered/sedimentary rocks. The sedimentary rocks that have been analyzed at the surface of Mars all contain igneous minerals, including olivine and feldspar, such as Windjana in Gale crater (Fig. 1, Treiman et al., 2016). In the search for life on Mars, sedimentary and hydrothermally altered rocks are critical targets (Hays et al., 2017). Igneous rocks - especially basaltic rocks and minerals and their alteration products can provide nutrients and habitats for microbes, and thus, are critical for assessing potential biosignatures (e.g., Hausrath et al., 2007; Baumeister et al., 2015; Cockell et al., 2019). Redox 
reactions occurring in igneous rocks can be used for energy and basaltic terrestrial analogue studies show that life can thrive in volcanic environments (Adcock et al., 2018; Des Marais et al., 2005). Specific igneous phases such as phosphates and hydrated silica provide essential nutrients for life and can host biosignatures, respectively (Adcock \& Hausrath, 2015; Costello et al., 2020).

\section{Recommendations: The case for studies of igneous rocks:}

Due to the importance of the study of martian igneous compositions highlighted above, we urge the decadal survey to recommend:

1. To sustain funding for meteorite recovery in order to have continued access to martian samples. We recommend the continued support of the Antarctic Search for Meteorites program (ANSMET) mission (see Ishii et al. white paper). In addition, meteorites recovered in the Northwest Africa (NWA) desert, one of the main locations where meteorites are recovered on Earth, are not currently easily accessed by the community and we recommend a better curation plan possibly managed by NASA for better accessibility. The improved understanding of the martian interior and surface through meteorites (Udry et al. 2020) highlights the fact that it is imperative to collect and study igneous samples.

2. To support the return of igneous samples from Jezero crater (see white paper by McSween et al. "Why Mars Sample Return is a Mission Campaign of Compelling Importance to Planetary Science and Exploration"). We recommend returning Hesperian-Noachian igneous pristine and dateable samples as well as variably altered igneous samples to address the Goal III (Understand the origin and evolution of Mars as a geological system) of the iMOST report.

3. To support funding for detailed analyses of igneous rocks at the martian surface. These rocks represent protoliths of sedimentary/altered rocks. The discovery of igneous lithologies on Mars from basaltic to felsic and alkaline rocks shows a newly revealed diversity. However, it is still challenging to interpret these rocks remotely, both from orbit and on the ground, due to the current spatial resolution and precision of these measurements. Continued funding for surface and orbital chemical and mineralogical sensors with better spatial resolution, or additional capabilities (e.g. micro-chemical imaging), and participating scientists to use existing instruments, should be a priority.

4. To support laboratories and collaborations between sample, remotesensing, and mission scientists. Igneous rocks on Mars are studied at various scales at many laboratories and institutions using different datasets: from microscopic to global scales. The collaboration between scientists working on samples (microscopic and hand sample scale), surface analyses (outcrop scales), and orbital analyses (large outcrop to 
global scales) is necessary in order to link all available datasets of igneous compositions to better constrain the overall martian planetary evolution than a single method or dataset could by itself. Funding laboratories at various institutions is critical and will ensure continued state-of-the-art sample analyses and collaborations between the various fields.

5. To support curation facilities needed for not only meteorite samples, but also Mars sample return, which will include a range of potentially temperature and humidity sensitive materials (see CAPTEM white paper by Stroud et al. and MSR Science Planning Group's Phase-2 activities).

\section{Significance to planetary science:}

Unraveling the evolution of Mars through the study of igneous rocks will help better constrain its entire geology as a complex planetary system, including its interior processes, climate, and potential past life. We therefore recommend an emphasis on the study of igneous rocks in the next planetary decadal survey. By studying igneous compositions, and thus Mars as a whole, including its formation, interior, climate, and habitability, we can answer MEPAG questions to integrate "Goals to Understand Mars and Beyond": How do planetary surfaces, crusts, and interiors form and evolve?; How do climates and atmospheres change through time?; What are the pathways that lead to habitable environments across the solar system and the origin and evolution of life?; How is the solar system representative of planetary systems in general?

\section{References:}

Adcock, C. T., \& Hausrath, E. M. (2015). Astrobiology, 15(12), 1060-1075; Adcock, C. T., et al. (2018). Am. Min., 103, 502-516; Baumeister, J. L., et al. (2015). Applied Geochemistry, 54, 74-84; Christensen, P. R., et al. (2005). Nature, 436(7050), 504-509. 5; Costello, L. J., et al. (2020). Geochemistry, 2819(20), 125613; Cousin A., et al. (2017) Icarus, 288, 265-283; Filiberto, J., et al. (2019). In Volatiles in the Martian crust (pp. 13-33). Elsevier; Forni O., et al. (2015) GRL, 42, doi:10.1002/2014GL062742; Gellert, R., et al. (2006). JGR: Planets, 177(2); Goudge, T. A., et al. (2015). JGR: Planets, 120(4); Hausrath, E.M., et al. (2007) Geobiology, 5, 49-61; Hays, L. E., et al. (2017). Astrobiology, 17(4), 363-400; Ishii, H. A., Corrigan C. M., et al. (2020) White paper; Des Marais, D. J., et al. (2005). In LPSC Conference XXVI (p. Abstract \#2353); McSween, H. Y., et al. (2006). JGR, 717(E9), E09S91; McSween, H. Y., et al. (2020) White paper; Rogers, A. D., \& Hamilton, V. E. (2015). JGR: Planets, 120(1), 62-91; MSPG (2019) Summary of the 2019 Work of the MSR Science Planning Group (MSPG), https://mepag.jpl.nasa.gov/reports.cfm; Salvatore, M. R., et al. (2018). Icarus, 301, 76-96; Sautter, V., et al. (2015). Nature Geoscience, 8(8), 605-609; Schmidt, M. E., \& McCoy, T. J. (2010). EPSL, 296(1-2), 67-77; Squyres, S. W., et al. (2006). JGR: Planets 717(2); Stolper E. M., et al. (2013). Science, 341, DOI: 10.1126/science.1239463; Stroud R., et al. (2020) White paper; Taylor, G. J., et al. (2010). Geology, 38(2), 183-186; Treiman, A. H., et al. (2016). JGR: Planets, 127(1), 75-106; Udry, A., et al. (2018). JGR: Planets, 123(6), 1525-1540; Udry, A., et al. (2020). ESSOAR, 55. https://doi.org/10.1002/essoar.10503123.1; Werner, S. C. (2009). Icarus, 201(1), 44-68; Westall, F., et al. (2018). Astrobiology, 18(3), 259-293. 